\title{
QUALIMETRIC ASSESSMENT OF INVESTMENT ATTRACTIVENESS OF THE REAL ESTATE PROPERTY
}

\author{
Svetlana Pupentsova, assoc. prof., PhD \\ Graduate School of Industrial Management and Economics \\ Peter the Great St. Petersburg Polytechnic University \\ e-mail:pupentsova_sv@spbstu.ru \\ Maria Livintsova, assoc. prof., PhD \\ Graduate School of Industrial Management and Economics \\ Peter the Great St. Petersburg Polytechnic University \\ e-mail: livintsova_mg@spbstu.ru
}

\begin{abstract}
In this paper, an algorithm was proposed to define the integral quality coefficient of real estate (on the example of office centers) according to a property tree in the framework of qualimetric modelling. The aim of the paper is an attempt to apply qualimetric methods to evaluate the investment attractiveness of real estate property.

When building a qualimetric model, information about the current state of the real estate market was gathered, and a survey of brokers and tenants of office centers was conducted to determine the quality of the selected properties. Scales which were developed to measure simple features of the real estate and evaluate the main price forming factors are presented.

The researchers proposed a model that takes into account the most essential characteristics of office real estate to determine rental rates and the rate of return on investment capital.
\end{abstract}

Key words: Qualimetric modelling, Criterion of investment attractiveness of the real estate property, Rental rate, Rate of return on capital.

JEL Classification: C25, D12, D40, D90.

Citation: Pupentsova S., Livintsova M., 2018, Qualimetric Assessment of Investment Attractiveness of the Real Estate Property, Real Estate Management and Valuation, vol. 26, no. 2, pp. 05-11.

DOI: 10.2478/remav-2018-0011

\section{Introduction}

Management decisions in the sphere of attracting investments in the construction, modernization and reconstruction of the real estate property, as a rule, are made on the basis of indicators of the efficiency and profitability of the undertaking. In this paper, the investor-friendly usage of a real estate property will imply the most efficient usage of the land plot and improvements. I.e. an effective option is a probable, legal, physically possible, economically feasible and financially viable option that leads to the maximum productivity and higher value of the real estate object.

Profitability (or rate of return on capital), as a major criterion of investment attractiveness, depends mainly on the qualitative and quantitative properties of the object itself. The construction of the dependence between the rate of return on capital and the main characteristics of an object will allow analysts to determine the optimal set of the property characteristics when profitability is maximal.

The paper proposes to change the set of descriptive characteristics of the real estate property by the integral quality coefficient of the object which was determined by the qualimetric modelling 
technique (OzEROV 2007).

Qualimetry is a scientific discipline which studies the methodology of the quantitative measurement of the quality of various objects. It is based on the modern methods of assessing the quality and technology level of products (LOBANOv 2014; POLTAVSKIY et al. 2016; NAZAROV, KRUSHNYAK 2006) and intangible assets (SUDYN 2015). Qualimetric modelling can be applied in the real estate property valuation along with other methods (PAGOURTZI et al. 2003; LIESER\& GROH 2014).

A qualimetric model is a hierarchical, multi-level model of the quality of an object - a so-called property tree (AZGALDOV 2015). It combines properties, weighting factors, rejected (the lowest possible) and referenced (the maximum possible) values for all properties, and a method calculating the integral quality coefficient (IQC) or quality evaluation method. The methodology of qualimetry can be found in Azgaldov's works (2008, 2011, 2015).

The qualimetric model reflects an opinion of experts (expert method applied in the article of NIKISHINA, MORGUNOVA 2016). Verification of this opinion is carried out by describing the property tree of objects with known indicators of rental rates (or of the rate of return). When the integral quality coefficient is received for each object of the sample, the dependence of the indicator on the calculated ratio is built. The construction of a significant regression dependence demonstrates the applicability of this qualimetric model in practice.

\section{Methodology of the qualitative evaluation of office centers}

To start developing a property tree for high-classes office centers (" $\mathrm{A}$ " and " $\mathrm{B}$ " classes), it should be noted that a qualimetric model for this specified market segment has already been described (KuZNETSOV 1999; ANTONOV et al. 2006; CIESLAK et al. 2014; MiRZOYAN 2015). The novelty of the proposed model is that, when constructing a three-level property tree and developing a scale for each simple characteristic from the rejected to the referenced object, the following were taken into consideration:

- the modern classification of the market of office centers that was created by St. Petersburg Research Forum. Members of the St. Petersburg Research Forum are Maris | Part of the CBRE Affiliate Network, Colliers International, Jones Lang LaSalle and Knight Frank;

- the current market position of the analyzed segment (in 2016);

- the opinions of brokers and tenants of the office centers (survey of Maris | Part of the CBRE Affiliate Network).

The hierarchical structure of the property tree reflects the interaction and interdependence of simple and complex properties. The weighting factors were rated for each tier of the hierarchy while creating the property tree. The designed system of preferences of some properties of an object over others makes it possible to take into account the subjective attitude of experts to selected price forming factors. The final adjusted weight of each property was determined as the product of the weights of the first and second level. The hierarchical structure and the weighting coefficients assigned by the experts to each of the selected factors has been presented in Table 1.

Ten office centers of the " $A$ " class and twenty office centers of the "B" class in St. Petersburg (Russia) were described according to this property tree. The actual rental rates for each sampled object were obtained for the second quarter of 2016 (survey of Maris | Part of the CBRE Affiliate Network). The integral quality coefficient (further IQC) was defined to reflect the quality of the object as a set of its properties. The IQC takes a value from 0 to 1 . This parameter is calculated by "convolution" of the indicators of individual properties by using the weighted average arithmetic mean formula:

$$
I Q C_{j}=\sum\left(K_{i j} \times G_{i}\right),
$$

where $K_{i j} \quad$ - a relative parameter of the property (factor),

$j \quad=1, \ldots, m ; m$ is the number of the object;

$G_{i} \quad$ - weight of the $i$-th price forming factor $(i=1, \ldots, n ; n$ - the number of object properties).

${ }^{1}$ http:// www.colliers.com/ru-ru/stpetersburg/insights/company-news/2014/2014-11-26-real-estate-forum-16december. 


\section{S sciendo}

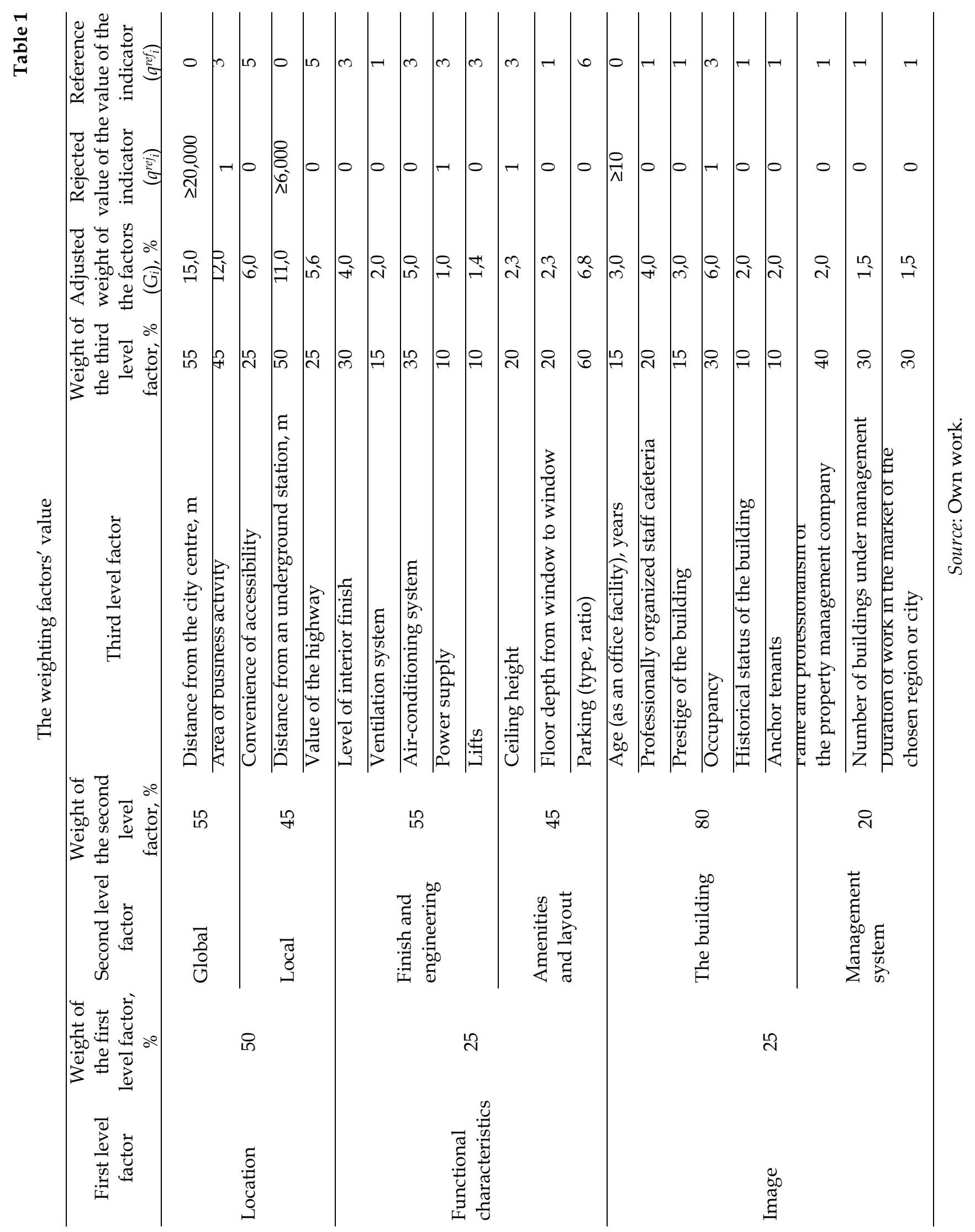




\section{S sciendo}

The relative measure of the property $\left(K_{i j}\right)$ is computed by the formula:

$$
K_{i j}=\frac{Q_{i j}-q_{i}^{r e j}}{q_{i}^{r e f}-q_{i}^{r e j}},
$$

where $Q_{i j}$ - absolute index of the $i$-th price forming factor (elementary or simple property) of the $j$-th evaluation object; $q^{r e j}{ }_{i}$ - rejected value of the indicator, defined as the lowest of all possible values; $q^{r e f}{ }_{i}$ - reference (benchmark) value of the indicator, defined as the best of all possible values.

Presented below is a scale which was developed to measure simple properties $Q_{i j}$ for an office center on the basis of Table 1. For example, the distance from the city center is assumed to be measured in meters in a straight line from the office center to the center of the city. In this case, the reference business center will be located in the area of the city center and the reference value of this indicator for such an object $\left(q^{\text {ref }} i_{i}\right)$ will be taken as equal to zero. The rejected value of the indicator $\left(q^{r e j} j_{i}\right)$ will be equal to the maximum possible distance from the business center to the center of the city in meters. In this research, this corresponds to 20,000 meters or more. In the same way, the distance from the underground station is convenient to estimate in meters in a straight line for model design. The benchmarked object is situated near an underground station and the distance is assigned to zero meters, or there is an adequately organized shuttle-bus service for this object. If the distance from the nearest underground station to the office center building is equal to 6,000 meters or more, then it is the rejection object.

The age of a building serving as an office facility is convenient to measure in years when constructing the qualimetric model. A reference value for the object, with a maturity of up to one year, is coded as " 0 ". Then the code increases depending on the actual operating period: 10 years or more corresponds to the rejected value of this indicator for the object.

It is proposed to use a nominal scale to describe a simple property of the object. In this case, the maximum possible code is given to the reference object, while a value of zero is assigned to the rejected one. For example, vehicle and public transport access to a building is possible to estimate on a scale from " 0 " - very inconvenient that corresponds to the rejected object to " 5 " - very convenient access that corresponds to the reference object. The value of the highway classified according to vehicle traffic is also proposed to be encoded on a scale from " 0 " to " 5 ".

Parking as the most significant factor for office centers is proposed to be expressed as:

" 0 " - non-existing, which corresponds to the rejected object;

"1" - surface unsecured guest parking with a parking ratio of more than 100 (for example, one parking space per 100 sq. $\mathrm{m}$ of a rentable area);

"2" - surface unsecured guest parking with a parking ratio of less than 100 (for example, one parking space per 70 sq. $\mathrm{m}$ of a rentable area);

" 3 " - surface secured parking with a parking ratio of more than 100;

" 4 " - surface secured parking with a parking ratio of less than 100;

" 5 " - underground parking or multilevel parking with covered walkway to the building, with a parking ratio of more than 100;

" 6 " - underground parking or multilevel parking with covered walkway to the building with a parking ratio of less than 100 , corresponding to the reference object.

Level of interior finish in modelling is presented in four groups:

" 0 " - rough finish (aligned walls and floors) refers to the rejected object,

" 1 " - office fit-out requiring repair,

"2" - classic office finish (painted walls, Armstrong metal ceiling, trim flooring: carpet or linoleum, gypsum plasterboard or glass partitions),

"3" - expensive high-quality modern finish corresponding to the reference object.

The estimation of the air-conditioning system also can be divided into four groups:

" 0 " - system is absent (the rejected object);

"1" - part of the premises is equipped with air-conditioning (split-systems);

" 2 " - all of the premises are equipped with air-conditioning (split-systems);

" 3 " - central air-conditioning (the reference object).

The reference object is equipped with modern high quality speedy lifts of major international brands. Intermediate codes are assigned to buildings equipped with modern lifts, but of insufficient quantity, and with outdated lifts. The rejected value is given to buildings higher than 3 floors without lifts. 
The rejected value for some properties of the object is possible to estimate with a score equal to " 1 ". Thus, it is proposed that the area of business activity is encoded depending on the environment of the object:

Index " 1 " is when there are objects that can have a negative impact on the image of a nearby building (for example: a functioning industrial buildings, cemeteries, landfills, prisons, etc.). Such an environment corresponds to the rejected object;

Index "2" refers to an environment that has a neutral impact onto the office center (sleeping areas of the city, residential development);

Index " 3 " signifies an environment that positively affects the object (developed area of business activity). Good building location corresponds to the reference object.

The power supply system is characterized by the classification of the Guild of Property Managers and Developers (GMD) that highlights three categories of reliability.

As far as the ceiling height is concerned, the reference value is assigned to objects that are over 3.0 meters high, an intermediate value is in the range of 2.6-3.0 meters, while for the rejected object - it is up to 2.6 meters.

The occupancy of the reference office center should be more than $90 \%$; an intermediate value is from $60 \%$ to $90 \%$. And the object will be considered as rejected if its occupancy is less than $60 \%$.

Properties such as "Ventilation system", "Floor depth", "Organized staff cafeteria", "Prestige of the building", "Historical status of a building", "Anchor tenants", "Fame and professionalism of the property management company", "Number of buildings under management" enter the qualimetric model as Code " 0 " to the rejected object, and as Code " 1 " to the reference object.

For example, the ventilation system can be presented by two groups: 1) the natural system and 2) the central supply and exhaust ventilation system.

Floor depth from window to window of up to 22 meters is more convenient when planning internal office space and for further exploitation. This characteristic is therefore related to the reference object. If this option is more than 22 meters, then business center can be attributed to a group of the rejected objects.

It is possible to speak about the prestige of the building if a property is well-known to a wide range of potential consumers of business center services. The higher status of the reference building "with a history" and the presence of anchor tenants (or the well-known companies in the market) allow the property to be shown more profitably during its market promotion.

Fame and professionalism of the property management company for the reference object are determined when this object is managed by a famous well-organized or relevant international experienced property management company (or the owner) that has been working on the market for more than 3 years. If a professional property management company has more than 5 buildings under management (not less than 5,000 sq. m each), this allows them to reduce operating costs.

The resulting property tree will help to describe any business center in the chosen market. The convolution of the individual properties according to Formula (1) will allow us to calculate the IQC of any object by comparing its properties with the parameters of the reference and rejection objects that have been shown in Table 1. As mentioned above, the integral quality coefficients were calculated for ten office centers of the " $\mathrm{A}$ " class and twenty office centers of the " $\mathrm{B}$ " class on the basis of the property tree shown in the Table 1. The market rental rates are known for these objects. Rental rates of sampled objects and the integral quality coefficients calculated for these objects by Formula (1) are correlated in Figure 1.

The conclusion that the market confirms the selection of price forming factors selected for the qualimetric model was made on the basis of a high determination coefficient of regression of the office center sample rental rates from the IQC of the object. Thus, the linear function and confidence interval presented in Figure 1 can be used to determine the market rental rate for " $A$ " and " $B$ " class office centers.

It should be noted that class " $\mathrm{A}$ " office centers have an IQC in the range of 0.83-0.9. This means that the offered property tree allows professional real estate market participants to adjust the class of office centers stated by the owner.

Qualimetric modelling is proposed for use in the assignment of rates of return on capital (PUPENTSOVA 2007). Let us explore the application of the above-presented property tree (Table 1) in order to determine the rate of return on capital. It should be noted that the technique of extraction is 


\section{S sciendo}

one of the most reliable and demonstrative methods of determining the rate of return on capital obtained on the basis of the agreed internal rate of return (IRR) for similar projects (see OzEROV 2007).

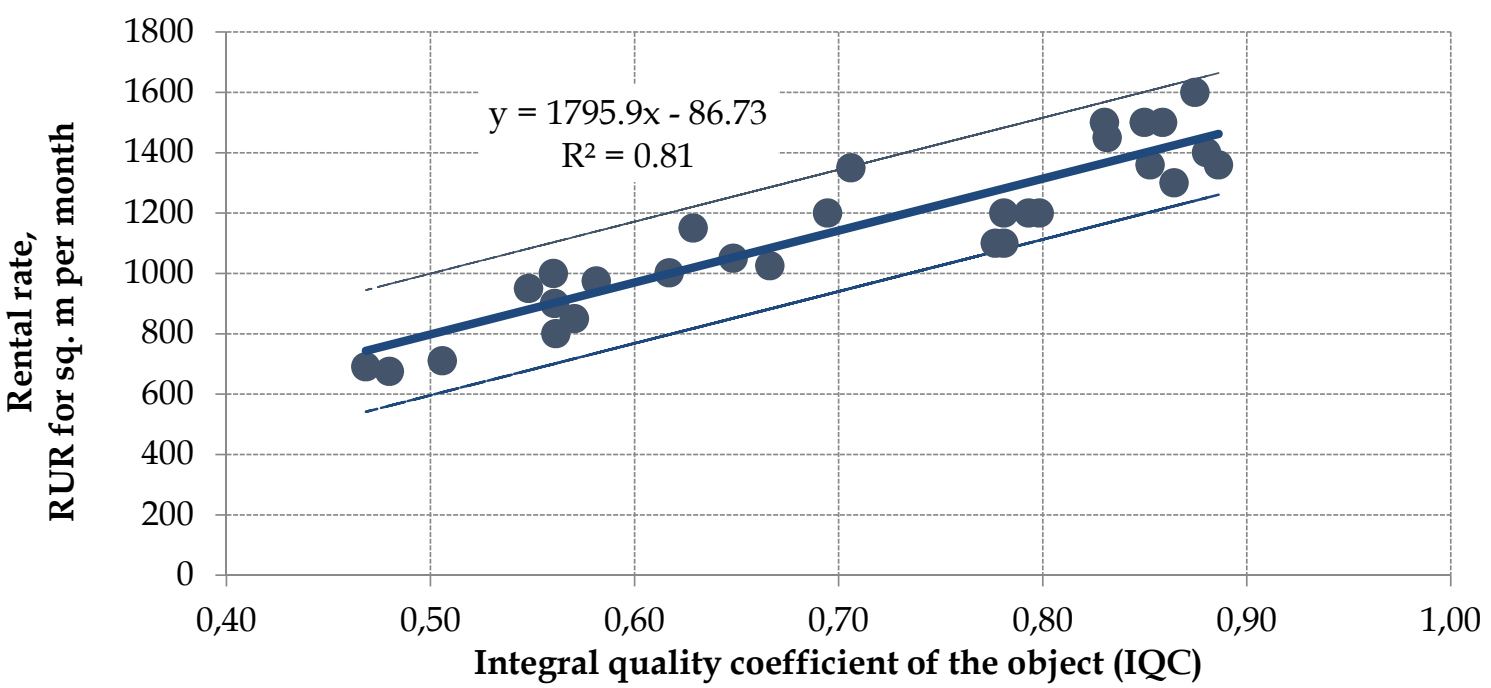

Fig. 1. The dependence between rental rates and IQC. Source: own study.

In this research, cash flows from rental income were constructed and the resulting internal rate of return (IRR) was received for thirty business centers to which the offer price and rental rate were known. The formula for calculating the internal rate of return is given in the former publications (PUPENTSOVA 2007, p. 48).

The obtained values of the integral quality coefficients resulted in the dependence which is shown in Figure 2 below, where the internal rate of return of the sampled business centers is shown on the Yaxis, and the IQC is shown on the $\mathrm{X}$-axis.

A clearly expressed dependence of the rate of return on capital from the IQC of the object is recommended in order to assign a rate of return on invested capital in the analyzed market segment.

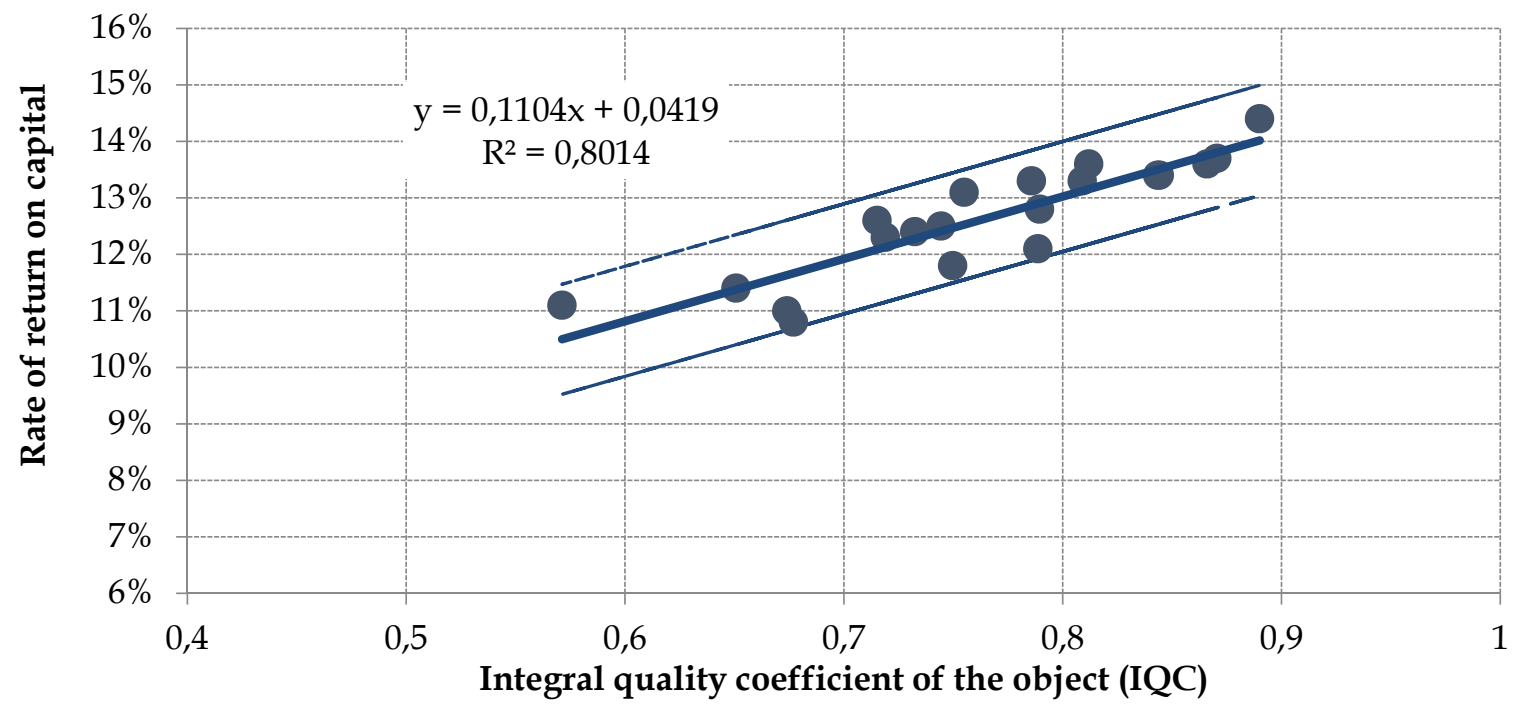

Fig. 2. The dependence between the rate of return on capital and IQC. Source: own study.

\section{Discussion of the results and conclusions}

Thus, the integral quality coefficient of the object calculated on the basis of the property tree shown in Table 1 can act as a criterion for the investment attractiveness of the object. Moreover, the analysis and processing of the market information have shown that an upgrade of the class and improvement of the qualitative characteristics of the object increase its rental yield (profitability), i.e. the higher the integral quality coefficient of the object, the higher its rental rate and, consequently, its investment attractiveness.

It is proposed that a rapid assessment of the investment attractiveness of real be carried out using 
the regression equations presented in Figures 1 and 2. The integral quality coefficient of the evaluated object obtained on the basis of the property tree is substituted in the equation shown in Figure 1. As a result, the rental rate is determined, influencing the projected revenue and profit opportunities of the object. And vice versa, if the rental income is attractive to the investor, it will determine the set of characteristics of the future object.

The dependence obtained in Figure 2 will allow investors to determine the optimal set of the features of the designed property at which rental yield is maximal.

The confidence interval calculated for the regression of the internal rate of return on the project from the integral quality coefficient of the object can be used by professional real estate market participants in risk analysis when constructing possible scenarios for an investment project.

\section{References}

ANTONOV A.V., VECHER N.F., KuZnetsov D.D., 2006, “Kvalimetricheskoe modelirovanie ob'ectov kommercheskoy nedvigimosti s tsel'iu prinyatiya investitsionnyh resheniy (Qualimetrical Modelling of Commercial Real Estate with the Purpose of Making Investment Decisions)", St. Petersburg, Electronic resource [http:/ / www.ddk-spb.ru/nauchnaja-dejatelnost/seminary].

AzGaldov G.G., Kostin A.V., 2011, Applied Qualimetry: Its Origins, Errors and Misconceptions. Benchmarking: An International Journal, vol. 18, no. 3, pp. 428-444.

AzGALDOv G.G., 2015, The ABC of Qualimetry: The Toolkit for Measuring Immeasurable. Garry G. Azgaldov, Alexander V. Kostin, Alvaro E. Padilla Omiste; interpreter Eric Azgaldov. Ridero, 167 p. Electronic resource [http://www.labrate.ru/books/20150831_the_abc_of_qualimetry-text-cc-bysa.pdf].

Cieslak I., StrumiŁŁo-RembowsKa D., SzUniewicz K., 2014, Application of Qualimetric Methods for Evaluation of Urbanized Space Quality for Analyses of the Local Real Property Market. Journal of Real Estate Management and Valuation, Vol. 22, iss. 4. pp. 51-59.

KuZNETSOV D.D., 1999, “Tekhnika metoda sravnenia prodage: ot kachestvennyh korrektirovok k kvalimetricheskoy modeli (Technique of the Sales Comparison Approach: from Qualitative Adjustments to Qualimetric Model)". NEG "Real Estate Problems". Saint-Petersburg: Publishing house NP "RClub", iss. 1, pp. 108-115.

KVALIMETRICHESKAYA EKSPERTISA STROITELNIH OB'ECTOV [Qualimetric Examination of the Construction Facilities], ed. MARUGIN V.M. and AzGALDOV G.G., 2008, SPb.: Politechnika, p. 528.

LiESER K., \& GROH A.P., 2014, The Determinants of International Commercial Real Estate Investment. The Journal of Real Estate Finance and Economics, No. 48(4), pp. 611-659.

LOBANOV A.S., 2014, The present and Future of Qualimetry as a Scientific Discipline. Scientific and Technical Information Processing, Vol. 41, iss. 1, pp. 57-65, doi: 10.3103/S0147688214010122.

MiRZOYAN N.V., 2015, Analis priminenia sravnitelnogo podhoda $v$ sootvetstvii s federalnym standartom otsenki "Otsenka nedvigimosty (FSO № 7)" (Analysis of the Comparative Approach in Accordance with Federal Valuation Standard Number 7 «Real Estate Appraisal»). Property Eelations in the Russian Federation, No. 6 (165), pp. 66-77.

NAZAROV N.G., KRUSHNYAK N.T., 2006, What is Measured in Qualimetry? Measurement Techniques, no. 49(3), pp. 238-243.

NiKISHINA O.V., MORGUNOVA T.A., 2016, Otsenka investitsionnoy privlekatel'nosti objecta nedvigimosti. (Assessment of Investment Attractiveness of a Real Estate Object]. Izvestiya vuzov. Investitsii. Stroitelstvo. Nedvigimost, No. 2 (17), pp. 80-86.

OzEROV YE.S., 2007, "Ekonomicheskiy analiz i otsenka nedvizhimosti (The Economic Analysis and the Real Estate Assessment)". Saint-Petersburg: MKS, p. 536.

Pagourtzi E., Assimakopoulos V., HAtzichristos T., \& French N., 2003, Real Estate Appraisal: a Review of Valuation Methods. Journal of Property Investment \& Finance, No. 21 (4), pp. 383-401.

PoltavskiyA.V., Zhumabaeva A.S., Ayzharikov K.A., PivKin A.V., Telegin A.M., 2016. Decision Making Concept to Create Complex Technical Systems. Thereliability and quality of complex systems. No. 2 (14), pp. 74-84.

PuPENTSOVA S.V., 2007, "Modeli i instrumenty $v$ economicheskoy otsenke investitsiy (Models and Tools for the Economic Assessment of Investments]". Saint-Petersburg: MKS.

SUDYN Y., 2015, Innovative Methods of Evaluating Goodwill in Increasing the Competitiveness of the Company. Przedsiębiorstwo i region (Entrepreneurship and Region), No. 7, pp. 105-112, DOI: 10.15584/pir.2015.7.11. 